\title{
Review
}

\section{TLR signaling}

\author{
T Kawai ${ }^{1}$ and S Akira ${ }^{*, 1,2}$ \\ 1 Exploratory Research for Advanced Technology (ERATO), Japan Science and \\ Technology Agency, 3-1 Yamada-oka, Suita, Osaka 565-0871, Japan \\ 2 Department of Host Defense, Research Institute for Microbial Diseases, Osaka \\ University, 3-1 Yamada-oka, Suita, Osaka 565-0871, Japan \\ * Corresponding author: S Akira, Department of Host Defense, Research \\ Institute for Microbial Diseases, Osaka University, 3-1 Yamada-oka, Suita, \\ Osaka 565-0871, Japan. Tel: + 8166879 8303; Fax: + 8166879 8305; \\ E-mail: sakira@ biken.osaka-u.ac.jp
}

Received 06.10.05; accepted 28.11.05; published online 20.1.06 Edited by $\mathrm{G}$ Kroemer

\section{Abstract}

The Toll-like receptor (TLR) family plays an instructive role in innate immune responses against microbial pathogens, as well as the subsequent induction of adaptive immune responses. TLRs recognize specific molecular patterns found in a broad range of microbial pathogens such as bacteria and viruses, triggering inflammatory and antiviral responses and dendritic cell maturation, which result in the eradication of invading pathogens. Individual TLRs interact with different combinations of adapter proteins and activate various transcription factors such as nuclear factor (NF) $-\kappa \mathrm{B}$, activating protein-1 and interferon regulatory factors, driving a specific immune response. This review outlines the recent advances in our understanding of TLR-signaling pathways and their roles in immune responses. Further, we also discuss a new concept of TLR-independent mechanisms for recognition of microbial pathogens.

Cell Death and Differentiation (2006) 13, 816-825.

doi:10.1038/sj.cdd.4401850; published online 20 January 2006

Keywords: innate immunity; signal transduction; inflammatory cytokines; type I interferon; toll-like receptors

Abbreviations: AP-1, activating protein-1; ATF, activating transcription factor; CARD, caspase-recruiting domain; DCs, dendritic cells; ERK, extracellular signal-regulated kinase; FADD, Fas-associated death domain; IFN, interferon; $I \kappa B$, inhibitor of NF- $\kappa \mathrm{B}$; IPS-1, interferon promoter stimulator-1; IRAK, interleukin-1 receptor-associated kinase; IRF, interferon regulatory factor; JNK, c-Jun N-terminal kinase; LPS, lipopolysaccharide; MAL, MyD88adapter-like; MAVS, mitochondrial antiviral signaling protein; Mda5, melanoma differentiation-associated gene 5; MyD88, myeloid differentiation primary response protein 88 ; NF- $\kappa \mathrm{B}$, nuclear factor $\kappa \mathrm{B}$; pDCs, plasmacytoid DCs; RIG-I, retinoic acidinducible gene I; RIP1, receptor interacting protein 1; TAK1, transforming growth factor- $\beta$-activated protein kinase 1 ; TBK1, TANK-binding kinase; TIR, Toll/interleukin-1 receptor; TIRAP, TIR domain-containing adapter protein; TLR, Toll-like receptor; TNF, tumor necrosis factor; TRAF6, tumor necrosis factor receptor- associated factor 6; TRAM, Trif-related adapter molecule; Trif, TIR domain-containing adapter inducing IFN $\beta$; VISA, virus-induced signaling adapter

\section{Introduction}

Immune systems in vertebrates are divided into two basic categories: innate and adaptive immunity. Adaptive immunity, which is present in vertebrates, relies on antigen-specific receptors expressed on clonally expanded $T$ and $B$ lymphocytes that are generated by gene rearrangements and hyper mutations. The innate immune system is evolutionally conserved and is the first line of the defensive mechanisms for protecting the host from invading microbial pathogens. ${ }^{1}$ Until recently, innate immunity was considered as being nonspecific immune responses mediated by phagocytotic cells such as macrophages and neutrophils that engulf and lysis microbial pathogens. However, it has been demonstrated that mutant Drosophila carrying loss-of-function mutations in the Toll receptor results in high susceptibility to fungi infection and the defective induction of an antifungal peptide, providing the first evidence that Drosophila expresses a specific receptor responsible for sensing fungi infection. ${ }^{2,3}$ Subsequently, a human homolog of Toll (hToll) was identified, and showed that this protein has an ability to induce production of inflammatory cytokines and expression of costimulatory molecules. ${ }^{4}$ Remarkably, a loss-of-function mutation of mouse homolog of hToll was identified in lipopolysaccharide (LPS)-hyporesponsive mice. ${ }^{5,6}$ These pioneer studies opened new areas of research focused on the molecular mechanisms of the recognition of microbial pathogens and the activation of innate immune systems.

To date, 10 members of Toll-like receptors (TLRs) have been identified in human, and 13 in mice, and a series of genetic studies have revealed their respective ligands (Figure 1). ${ }^{7}$ For example, LPS of Gram-negative bacteria is recognized by TLR4 (hToll). ${ }^{5,6}$ TLR2, in concert with TLR1 or TLR6, recognizes various bacterial components, including peptidoglycan, lipopeptide and lipoprotein of Gram-positive bacteria and mycoplasma lipopeptide.$^{8-12}$ In particular, TLR1/ 2 and TLR2/6 discriminate triacyl lipopeptide and diacyl lipopeptide, respectively. TLR3 recognizes double-stranded RNA (dsRNA) that is produced from many viruses during replication. ${ }^{13}$ TLR5 recognizes bacterial flagellin. ${ }^{14}$ Mouse TLR11 recognizes yet unknown components of uropathogenic bacteria, and a profilin-like molecule of the protozoan parasite Toxoplasma gondii. ${ }^{15,16}$ TLR7 recognizes synthetic imidazoquinoline-like molecules, guanosine analogs such as loxoribine, single-stranded RNA (ssRNA) derived from human immunodeficiency virus type I (HIV-1), vesicular stomatitis virus (VSV) and influenza virus, and certain siRNAs. ${ }^{17-23}$ While mouse TLR8, which shows the highest homology to TLR7, is thought to be nonfunctional, human TLR8 mediates the recognition of imidazoquinolines and ssRNA. ${ }^{19-21}$ TLR9 


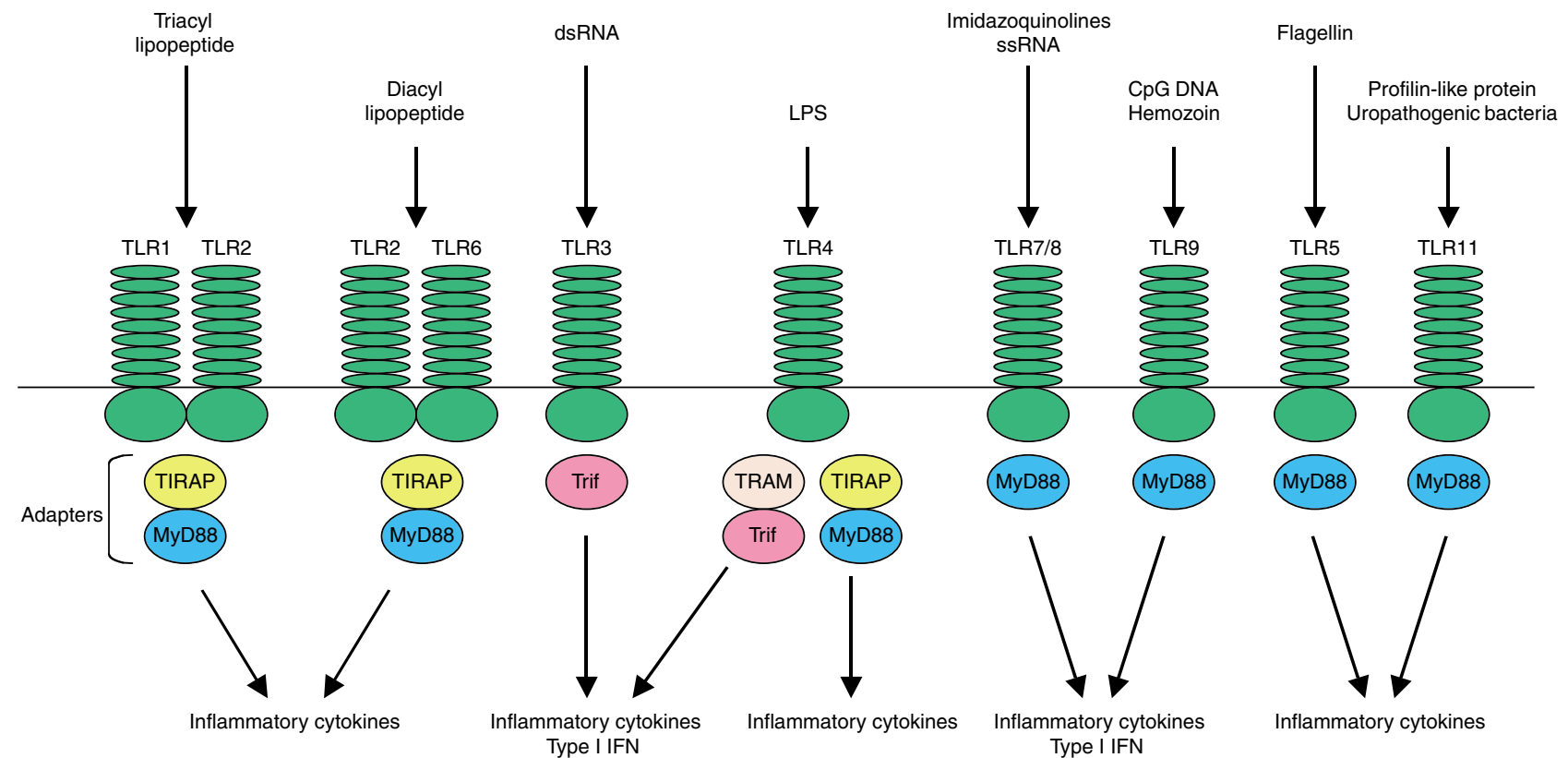

Figure 1 TLR-mediated immune responses. TLR2 in concert with TLR1 or TLR6 discriminates between the molecular patterns of triacyl and diacyl lipopeptide, respectively. TLR3 recognizes dsRNA. TLR4 recognizes bacterial LPS. TLR7/8 mediates recognition of imidazoquinolines and ssRNA. TLR9 recognizes CpG DNA of bacteria and viruses. TLR5 recognizes bacterial flagellin and mouse TLR11 recognizes components of uropathogenic bacteria and profilin-like molecule of the protozoan parasite Toxoplasma gondii. TLR1/2 and TLR2/6 utilize MyD88 and TIRAP/MAL as essential adapters. TLR3 utilizes Trif. TLR4 utilizes four adapters, including MyD88, TIRAP/MAL, Trif and TRAM. TLR7/8, TLR9, TLR5 and TLR11 use only MyD88. The MyD88-dependent pathway controls inflammatory responses, while Trif mainly mediates type I IFN responses. In addition, TLR7/8 and TLR9 induce type I IFN in a MyD88-dependent manner in pDCs

recognizes bacterial and viral CpG DNA motifs and malaria pigment hemozoin. ${ }^{24-27}$ After recognition of microbial pathogens, TLRs trigger intracellular signaling pathways that result in the induction of inflammatory cytokines, type I interferon (IFN) and chemokines (Figure 1). Moreover, signaling from TLRs induces the upregulation of costimulatory molecules on specialized antigen-presenting cells called dendritic cells (DCs). This process, called DC maturation, is essential for the induction of pathogen-specific adaptive immune responses, thus indicating that TLRs link innate and adaptive immunity. ${ }^{28}$ Importantly, TLRs activate a common signaling pathway that culminates in the induction of inflammatory cytokines such as tumor necrosis factor (TNF) $\alpha$, IL-6, IL-1 $\beta$ and IL-12, as well as alternative pathways that induce appropriate and effecter responses against different types of pathogens (Figure 1). ${ }^{29}$ In particular, TLR3, TLR4, TLR7, TLR8 and TLR9 induce antiviral responses by inducing type I IFN (IFN $\beta$ and multiple IFN $\alpha$ ) (Figure 1).

\section{Activation of NF- $\kappa$ B and AP-1 by the MyD88-Dependent Pathway}

TLRs contain extracellular leucine-rich repeats responsible for the recognition of pathogens, and the transmembrane and cytoplasmic Toll/interleukin-1 receptor (TIR) domains required for initiating intracellular signaling. ${ }^{29}$ All TLRs elicit conserved inflammatory pathways, culminating in the activation of nuclear factor (NF)- $\kappa \mathrm{B}$ and activating protein-1 (AP-1). $\mathrm{NF}-\kappa \mathrm{B}$ is a dimeric transcription factor that belongs to the
Rel-homology domain-containing protein family, which includes p65/RelA, p50/NF- $\kappa$ B1, p52/NF- $\kappa$ B2, RelB and $\mathrm{c}-\mathrm{Rel}^{30}$ The prototypical NF- $\kappa \mathrm{B}$ is thought to be a heterodimer composed of the p65 and p50 subunits in most types of cells. In unstimulated cells, NF- $\kappa \mathrm{B}$ is sequestered in the cytoplasm as an inactive form by interacting with inhibitor of NF- $\kappa \mathrm{B}\left(\mathrm{I}_{\kappa} \mathrm{B}\right)$ proteins. Upon stimulation with various TLR ligands, I $\kappa$ Bs are phosphorylated at serine residues by an IKK complex consisting of $\mathrm{IKK} \alpha$ and $\mathrm{IKK} \beta$ protein kinases and a regulatory molecule, IKK $\gamma / \mathrm{Nemo}$. The phosphorylation targets $\mathrm{I}_{\kappa} \mathrm{BS}$ for ubiquitination and degradation by the $26 \mathrm{~S}$ proteasome, allowing $\mathrm{NF}-\kappa \mathrm{B}$ to be released into the nucleus and to bind to the $\kappa \mathrm{B}$ site. AP-1 is a dimeric basic region leucine zipper (bZIP) protein composed of members of Jun, Fos, activating transcription factor (ATF) and the Maf subfamily, which bind TPA-response elements or cAMP-response elements. ${ }^{31}$ Among the AP-1 family proteins, c-Jun is thought to play central roles in inflammatory responses. AP-1 activation in TLR signaling is mostly mediated by MAP kinases such as cJun N-terminal kinase (JNK), p38 and extracellular signalregulated kinase (ERK). Many TLR ligands activate these MAP kinases in similar kinetics.

The proximal events of TLR-mediated intracellular signaling are initiated by TIR-domain-dependent heterophilic interactions with TIR-domain-containing cytosolic adapters such as myeloid differentiation primary response protein 88 (MyD88), TIR domain-containing adapter protein (TIRAP)/Mal, TIR domain-containing adapter inducing IFN $\beta$ (Trif) (also known as TICAM1) and Trif-related adapter molecule (TRAM) (also known as TICAM2) (Figure 1). ${ }^{7,29}$ MyD88 is a central adapter 


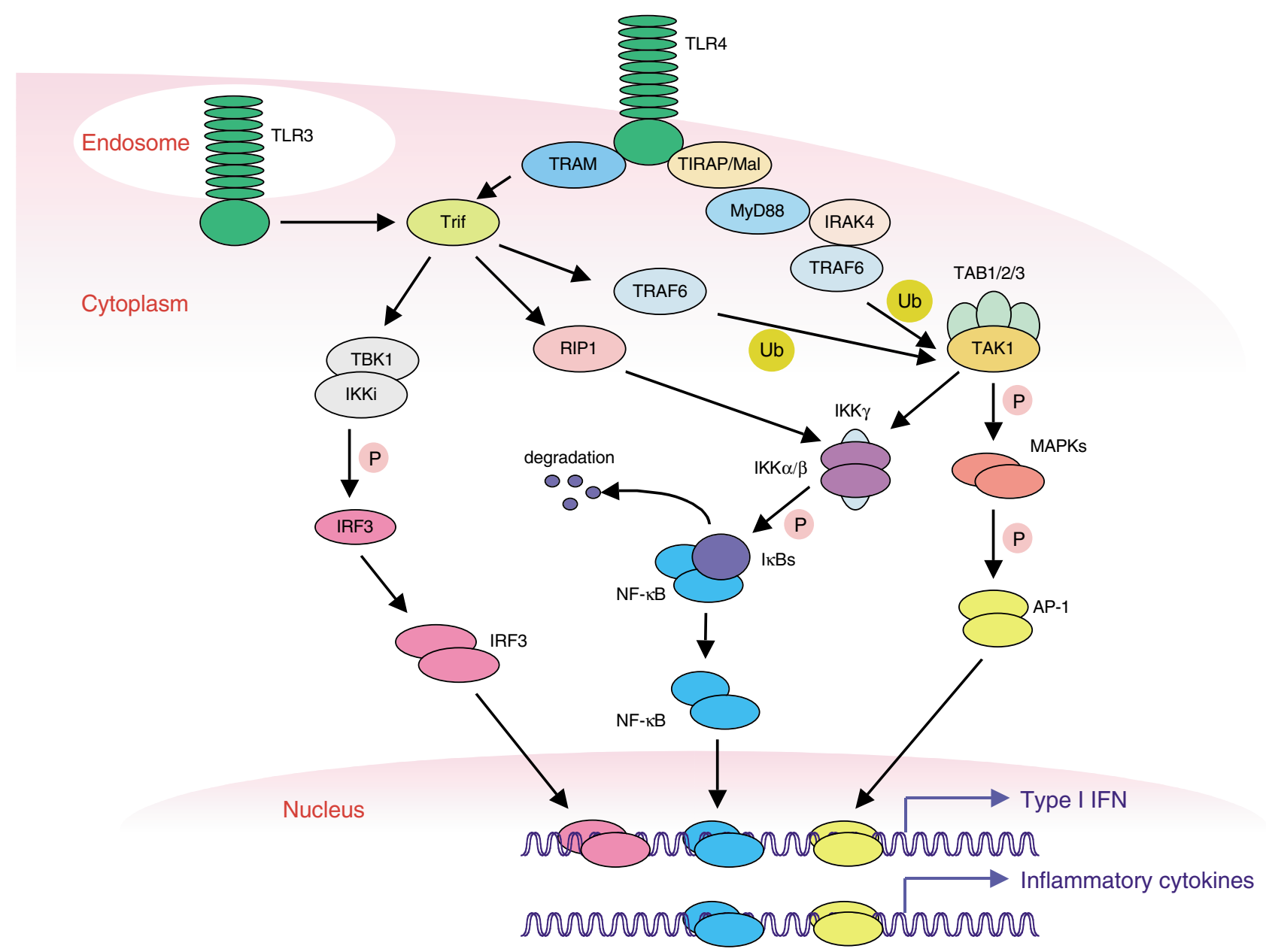

Figure 2 TLR3- and TLR4-mediated signaling pathways. TLR4 activates the MyD88-dependent and the Trif-dependent pathways. TIRAP/Mal and TRAM are required for the activation of MyD88- and Trif-dependent pathways, respectively. MyD88 recruits IRAK4 and TRAF6 upon ligand stimulation. TRAF6 activates TAK1/TAB1/TAB2/ TAB3 complex via K63-linked ubiquitination (Ub). Activated TAK1 complex then activates the IKK complex consisting of IKK $\alpha$, IKK $\beta$ and IKK $\gamma / \mathrm{Nemo}$, which catalyze $\mid \kappa B s(P)$. $\mid \kappa$ Bs are destroyed by the proteasome pathway, allowing NF- $\kappa$ B to translocate into nuclei. TAK1 simultaneously activates the MAP kinase pathway, which results in phosphorylation $(\mathrm{P})$ and activation of $\mathrm{AP}-1$. NF- $\kappa \mathrm{B}$ and $\mathrm{AP}-1$ control inflammatory responses by inducing proinflammatory cytokines. TLR4 also recruits TRAM and Trif, which interacts with TBK1. TBK1 together with IKKi mediates phosphorylation of IRF3 (P). Phosphorylated IRF3 is dimerized and translocated into nucleus to bind DNA. Trif also interacts with TRAF6 and RIP1, which mediate NF- $\kappa$ B activation. Activation of IRF3, NF- $\kappa$ B and AP-1 is required for induction of type I IFN, particularly IFN $\beta$. TLR3, which resides in endosomal vesicles, utilizes Trif but not MyD88, TIRAP/Mal and TRAM for its signaling. MAPKs, MAP kinases

shared by almost all TLRs. The association of TLRs and MyD88 recruits members of the interleukin-1 receptorassociated kinase (IRAK) family (Figure 2). So far, four IRAKs are identified: IRAK1, IRAK2, IRAK4 and IRAK-M. While IRAK1 and IRAK4 possess intrinsic serine/threonine protein kinase activities, IRAK2 and IRAK-M lack this activity, suggesting that they negatively regulate TLR-mediated signaling. IRAK-M-deficient cells consistently show hyperproduction of inflammatory cytokines in response to various TLR ligands. ${ }^{32}$ Furthermore, a model has been proposed in which IRAK-M prevents the dissociation of IRAK4 and IRAK1 from MyD88. ${ }^{32}$ Production of inflammatory cytokines in response to various TLR ligands is ablated in IRAK4-deficient mice. ${ }^{33}$ Furthermore, IRAK4 mutations are reported in patients with recurrent infections and poor inflammatory responses. ${ }^{34}$ These observations indicate the importance of IRAK4 in TLR signaling in both human and mouse. In response to stimuli, IRAK4 and IRAK1 are sequentially phosphorylated and dissociated from MyD88, which results in activation of tumor necrosis factor receptor-associated factor 6 (TRAF6) (Figure 2), which contains an N-terminal RING domain that is found in a number of E3 ubiquitin ligases, and forms a complex with Ubc13 and Uev1A, serving as the ubiquitin E3 ligase to promote synthesis of lysine 63-linked polyubiquitin chains. ${ }^{35}$ Lysine 63 -linked ubiquitination is shown to be associated with a number of cellular responses, including signal transduction and cellular localization. ${ }^{36}$ TRAF6 in turn activates transforming growth factor- $\beta$-activated protein kinase 1 (TAK1), a member of the MAP kinase kinase kinase (MAP3K) family, in a ubiquitin-dependent manner (Figures 2). ${ }^{35}$ TAK1 forms a complex with TAB1, TAB2 and TAB3. Especially, $T A B 2$ and $T A B 3$ bind lysine 63-linked polyubiquitin chains via zinc-finger domains, and these interactions are required for TAK1 activation. ${ }^{35}$ TAK1 activates the IKK 
complex that leads to NF- $\kappa \mathrm{B}$ activation (Figure 2). However, a direct substrate of TAK1 that is responsible for the IKK activation in TLR signaling remains unknown. TAK1 simultaneously phosphorylates two members of the MAP kinase kinase family, MKK3 and MKK6, which subsequently activate JNK and p38. ERK is also activated in response to TLR ligands through the activation of MEK1 and MEK2, although an upstream kinase activating MEK1 and MEK2 in TLR signaling remains unknown. Embryonic fibroblasts and $B$ cells derived from TAK1-deficient mice show reduced NF- $\kappa \mathrm{B}$, JNK and p38 activation in response to various TLR ligands. ${ }^{37}$ Furthermore, ERK1 and ERK2 activation was also reduced in TAK1-deficient $B$ cells. ${ }^{37}$ Thus, TAK1 is required for the activation of NF- $\kappa \mathrm{B}$ and MAP kinase family members in TLR signaling (Figure 2). Other members of MAP3K, MEKK3 and Tpl2 (also known as Cot1) are also implicated in the activation of MAP kinase activation in TLR4 signaling. JNK and p38 activation and IL-6 production in response to LPS are impaired in MEKK3-deficient cells. ${ }^{38}$ While JNK and p38 activation in response to LPS is intact in Tpl2-deficient macrophages, ERK activation and $\mathrm{TNF} \alpha$ production are severely impaired. ${ }^{39,40}$

The signaling pathway from MyD88 to the activation of NF$\kappa \mathrm{B}$ and AP-1 is utilized by almost all TLRs, and this MyD88dependent pathway controls inflammatory responses. However, the activation of the MyD88-dependent pathway requires an additional adapter TIRAP/Mal in terms of TLR2 and TLR4 signaling because TIRAP/Mal-deficient mice have defects in inflammatory responses mediated by TLR1/2, TLR2/6 and TLR4 ligands (Figure 1). ${ }^{41,42}$

\section{Activation of NF- $\kappa$ B and AP-1 by the Trif-Dependent Pathway}

Macrophages and DCs isolated from MyD88-deficient mice fail to activate $\mathrm{NF}-\kappa \mathrm{B}$ and MAP kinases and produce inflammatory cytokines in response to various TLR ligands, including TLR2, TLR5, TLR7 and TLR9, indicating that MyD88 is the sole adapter for these TLRs. ${ }^{14,17,43-45}$ MyD88-deficient cells also fail to produce inflammatory cytokines in response to LPS. ${ }^{46}$ However, LPS is still capable of activating NF- $\kappa \mathrm{B}$ and MAP kinases in MyD88-deficient mice; moreover, this activation in MyD88-deficient cells is delayed in reaching a peak in comparison with wild-type cells. ${ }^{46}$ Importantly, LPS can induce IFN $\beta$ production by macrophages and DCs in a manner independent of MyD88. ${ }^{43}$ Type I IFN, which are produced in response to virus infections or LPS, are key cytokines that induce an antiviral state in target cells, as well as facilitate antiviral adaptive immune responses. ${ }^{47}$ Together, these observations suggest that other adapters mediate late activation of NF- $\kappa \mathrm{B}$ and MAP kinases which is associated with type I IFN induction in TLR4 signaling. In such contexts, Trif was identified to be involved in the MyD88-independent pathway, and importantly has the ability to activate $\mathrm{NF}-\kappa \mathrm{B}$, MAP kinases and IFN $\beta$ promoter, in contrast to MyD88 and TIRAP/MyD88-adapter-like (MAL), which have no ability to activate IFN $\beta$ promoter. ${ }^{48,49}$ Trif-deficient mice show defective type I IFN in response to LPS. Early activation of NF- $\kappa \mathrm{B}$ and MAP kinases in response to LPS is normally observed in
Trif-deficient mice; thus, Trif plays a critical role in type I IFN induction in TLR4 signaling (Figures 1, 2) ${ }^{50,51}$ However, production of inflammatory cytokines was reduced in Trifdeficient mice, suggesting that both MyD88- and Trifdependent pathways are required for maximal induction of inflammatory cytokines in response to LPS, although it is unclear how a Trif-dependent pathway facilitates inflammatory responses.

While Trif appears to be utilized by TLR4, TLR4 does not directly interact with Trif. ${ }^{49}$ The fourth adapter, TRAM, is selectively involved in the TLR4-mediated pathway (Figure 1). In contrast to TIRAP/MAL, which mediates activation of the MyD88-dependent pathway, TRAM is required for the activation of the Trif-dependent pathway, indicating that TRAM is an adapter linking TLR4 to Trif (Figure 2). ${ }^{52}$

Responses to poly IC, a TLR3 ligand, are relatively normal in MyD88-deficient cells. It has been shown that TLR3 does not interact with MyD88; thus, MyD88 is not utilized by TLR3 signaling. All responses to poly IC, including inflammatory cytokine and type I IFN induction and activation of NF- $\kappa \mathrm{B}$ and MAP kinases, are ablated in Trif-deficient mice, whereas TRAM-deficient cells normally respond to poly IC. Collectively, Trif is the sole adapter utilized by TLR3 (Figure 2).

The C-terminal region of Trif contains Rip homotypic interaction motif (RHIM), which mediates interaction with members of the receptor interacting protein (RIP) family. ${ }^{53}$ Mutational analyses indicate that the RHIM in Trif is required for NF- $\kappa$ B activation. In cells lacking RIP1, TLR3-mediated $\mathrm{NF}-\kappa \mathrm{B}$ activation and subsequent induction of target genes were impaired, indicating that Trif-RIP1 interactions are responsible for $\mathrm{NF}-\kappa \mathrm{B}$ activation in TLR3 signaling (Figure 2). ${ }^{53}$ By contrast, RIP3 negatively regulates NF- $\kappa \mathrm{B}$ activation by interfering in the interaction between Trif and RIP1. ${ }^{53}$ Furthermore, cells doubly deficient for MyD88 and RIP1 fail to activate NF- $\kappa$ B in response to poly IC and LPS, suggesting that RIP1 is selectively involved in the Trifdependent NF- $\kappa$ B activation. ${ }^{54}$

Trif also activates NF- $\kappa$ B via different pathways. Trif possesses three typical TRAF6-binding domains in the $\mathrm{N}$-terminal region, which mediate interaction with TRAF6. Overexpression of dominant-negative TRAF6 inhibits Trifinduced NF- $\kappa$ B activation and a mutant Trif that does not bind TRAF6 is incapable of activating NF- $\kappa$ B (Figure 2). ${ }^{55}$ These observations suggest that Trif activates NF- $\kappa$ B by recruiting TRAF6. Both Trif-RIP1 and Trif-TRAF6 pathways might converge at the IKK complex to induce maximum activation of $\mathrm{NF}-\kappa \mathrm{B}$. TAK1-deficient $\mathrm{B}$ cells have defects in B-cell proliferation in response to poly $\mathrm{IC}$, suggesting the possible involvement of TAK1 in TLR3 signaling (Figure 2). ${ }^{37}$ Given that TAK1 is activated by TRAF6-dependent ubiquitination, TAK1 is likely to be involved in Trif-TRAF6-dependent NF- $\kappa \mathrm{B}$ activation. However, macrophages from TRAF6-deficient mice respond to poly IC, suggesting cell-type-specific roles of TRAF6 in TLR3-mediated NF- $\kappa$ B activation. ${ }^{56}$

\section{Activation of IRFs by TLR3 and TLR4}

As mentioned above, TLR3 and TLR4 activate the Trifdependent pathway, which leads to induction of type I IFN, 
particularly IFN $\beta$. Transcription of $\operatorname{IFN} \beta$ gene is tightly controlled by cooperative activation of several transcription factors, including NF- $\kappa \mathrm{B}, \mathrm{ATF} 2 / \mathrm{c}-J$ un, interferon regulatory factor (IRF) 3 and IRF7. ${ }^{47}$ While NF- $\kappa$ B and ATF2/C-Jun are activated by numerous stimuli such as TLR ligands, IL-1 $\beta$, TNF $\alpha$ and DNA damage, IRF3 and IRF7 are activated when cells are exposed to LPS, poly IC and virus infection, and mainly control type I IFN. IRF3 and IRF7 are structurally related proteins present in the cytoplasm in unstimulated conditions. Upon stimulation, these proteins become phosphorylated by noncanonical IKKs, TANK-binding kinase 1 (TBK) 1 (also known as T2K or NAK) and IKKi (also known as $\mathrm{IKK} \varepsilon$ ), translocating into the nuclei to regulate target gene expression. ${ }^{57,58}$ Embryonic fibroblast cells from TBK1-deficient mice show decreased IRF3 activation and IFN $\beta$ induction by poly IC, while IKKi-deficient cells show normal IRF3 activation. ${ }^{59-61}$ However, residual activation of IRF3 in TBK1-deficient cells is totally abolished in TBK1 and IKKi double-deficient cells, indicating that the functions of TBK1 and IKKi are redundant in fibroblast cells. ${ }^{60}$ While IRF3 is constitutively expressed, expression of IRF7 is weak in unstimulated cells and dramatically induced by stimulation with LPS, type I IFN or virus infections. Thus, initial induction of IFN $\beta$ is largely dependent on IRF3 activation. Secreted IFN $\beta$ acts on neighboring cells and activates the JAK-STAT pathway via type I IFN receptor to induce IRF7 expression, which results in the amplification of type I IFN induction through a positive feedback mechanism. While MyD88deficient cells show normal IRF3 activation in response to LPS and poly IC, Trif-deficient cells fail to activate IRF3. Moreover, Trif interacts with TBK1. Taken together, the Trif $>$ TBK1/IKKi $>$ IRF3 axis controls type I IFN induction in TLR3 and TLR4 signaling (Figure 2).

\section{Activation of IRFs by TLR7/8 and TLR9}

It is known that TLR7/8 and TLR9 ligands also trigger type I IFN induction by plasmacytoid DCs (pDC), a subset of DCs that are specialized to produce large amounts of type I IFN in response to TLR7/8 and TLR9 ligands and virus infections. ${ }^{62,63}$ These inductions have been shown to occur independently of feedback signaling. While pDCs deficient of IRF3 normally respond to these TLRs, type I IFN and inflammatory cytokine induction is totally abolished in MyD88and IRAK4-deficient pDCs. ${ }^{64-67}$ Unlike other types of DCs, pDCs constitutively express high levels of IRF7. ${ }^{68,69}$ Furthermore, treatment of pDCs with TLR9 ligands causes nuclear translocation of IRF7, and pDCs derived from IRF7-deficient mice are incapable of producing type I IFN in response to TLR7/8 and TLR9 ligands. ${ }^{64,65}$ Thus, IRF7 is an essential transcription factor that regulates type I IFN induction in pDCs. Importantly, IRF7 interacts with MyD88, IRAK1 and TRAF6 to form a signaling complex (Figure 3). ${ }^{65,66,70}$ Notably, IFN $\alpha$ production and IRF7 activation in response to TLR7 and TLR9 ligands are abolished in IRAK1-deficient pDCs. ${ }^{70}$ Furthermore, in vitro experiments have clearly demonstrated that IRAK1, but not IRAK4, has an ability to phosphorylate IRF7. ${ }^{70}$ In contrast, pDCs deficient in IRAK1 show normal responsiveness to TLR7 and TLR9 ligands with respect to NF- $\kappa \mathrm{B}$ and
MAP kinase activation and inflammatory cytokine production. ${ }^{70}$ Thus, IRAK1 specifically mediates IRF7 activation downstream of MyD88 and IRAK4 (Figure 3). Moreover, TRAF6 E3 ubiquitin ligase activity is required for IRF7 activation, although the role of TRAF6-dependent ubiquitination remains unclear (Figure 3). ${ }^{65}$

It is also reported that IRF5 interacts with MyD88. ${ }^{71}$ Unexpectedly, IRF5 is essential for inflammatory cytokine induction rather than type I IFN induction by TLR4, TLR7, TLR9 and TLR3 in mice. IRF5 translocates into the nucleus in response to ligand stimulation. In the nucleus, IRF5 binds ISRE motifs present in the promoter region of inflammatory cytokine genes and causes their expression, probably through the coordinated activation with NF- $\kappa \mathrm{B} .{ }^{71}$ Although it is reported that IRF5 is phosphorylated by TBK1 and IKKi in vitro, cells deficient in TBK1 and IKKi show normal inflammatory responses in response to various TLR ligands. ${ }^{60,72}$ As mentioned above, an IRAK1 deficiency does not affect production of inflammatory cytokine. Thus, it is possible that as yet-unknown protein kinases that might associate with MyD88 are responsible for IRF5 phosphorylation and activation. It also remains unclear how TLR3, which does not utilize MyD88, activates IRF5 to control inflammatory cytokine induction. In contrast, human IRF5 is suggested to selectively participate in TLR7-mediated type I IFN induction, rather than inflammatory cytokine induction, suggesting species-specific function of IRF5. ${ }^{73}$

IRF8 is implicated in TLR9-mediated responses. In IRF8deficient pDCs, both type I IFN and inflammatory cytokines induced by TLR9 ligand are abolished. ${ }^{74}$ In these cells, the NF- $\kappa$ B DNA-binding activity in response to TLR9 ligand was severely impaired, suggesting that IRF8 activates NF- $\kappa$ B in pDCs. ${ }^{74}$

\section{Recognition of Viral Components by Non-TLR Sensors}

TLR3, TLR7/8 and TLR9, all of which recognize viral components and have abilities to induce type I IFN, are exclusively localized to endosomal compartments, but not on cell surfaces. ${ }^{7}$ This suggests that these TLRs recognize nucleic acids released into endosomes after virus or bacteria are internalized and lysed. However, once viruses directly enter into the cytosol and initiate replication to produce dsRNA, TLRs would no longer be able to sense viruses. It is reported that RSV infection triggers type I IFN induction in pDCs in a MyD88-independent manner. ${ }^{75}$ This induction is entirely dependent on virus entry into cytosol and replication. Furthermore, while pDCs recognize HSV-1 genomic DNA via TLR9, there is no increase in HSV-1 replication in TLR9deficient mice after local infection. ${ }^{76}$ Adaptive immune responses after murine cytomegalo virus (MCMV), vesicular stomatitis virus (VSV), lymphocytic choriomeningitis virus (LCMV) and reovirus infections are not affected in the absence of TLR3. ${ }^{77}$ Fibroblasts or conventional DCs derived from TLR3-deficient mice are capable of producing IFN $\beta$ following intracellular administration of poly IC and infection with Sendai virus (SeV), Newcastle disease virus (NDV) and VSV. ${ }^{60,78,79}$ Together, these observations strongly suggest 


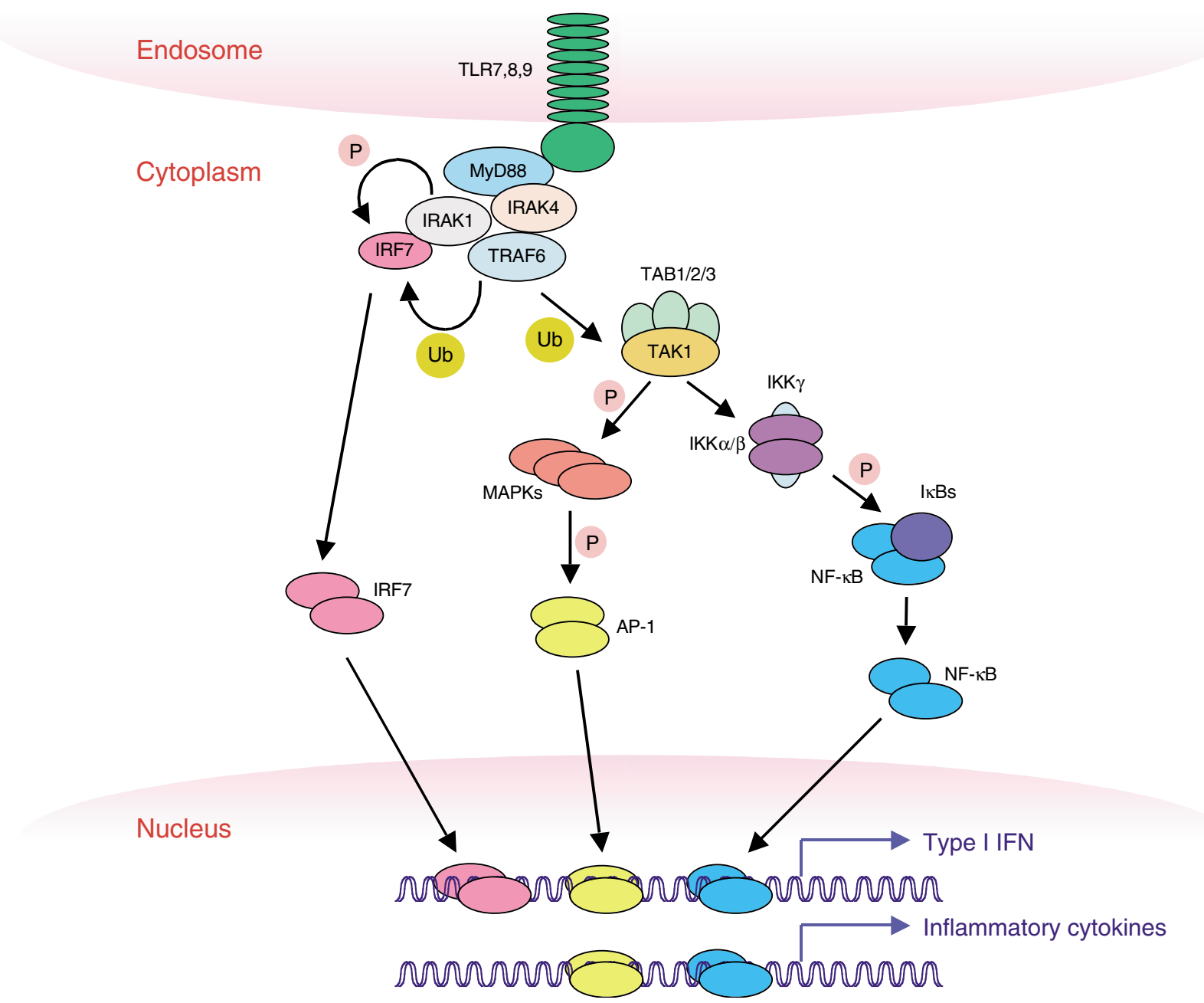

Figure 3 TLR7/8- and TLR9-mediated signaling pathway. TLR7/8 and TLR9 are expressed in endosomal compartments. After ligand ligation, these TLRs elicit the MyD88-dependent pathway to regulate inflammatory responses by activating NF- $\kappa$ B and AP-1. In pDCs, IRF7 is constitutively expressed and forms a signaling complex with MyD88, IRAK1 and IRAK4. In response to ligand stimulation, IRF7 is phosphorylated by IRAK1, dimerized and translocated into nuclei. Additionally, TRAF6dependent ubiquitination is also required for IRF7 activation. IRF7, together with NF- $\kappa$ B and AP-1, regulates expression of type I IFN, including IFN $\alpha$ and IFN $\beta$

that host cells express cytoplasmic sensors that can detect actively replicating viruses. In these scenarios, a cytoplasmic protein, namely retinoic acid-inducible gene I (RIG-I), was identified through a functional screening. ${ }^{79} \mathrm{RIG}-\mathrm{I}$ is a DExD/H box RNA helicase containing two caspase-recruiting domain (CARD)-like domains. The helicase domain interacts with dsRNA, whereas the CARD-like domains are required for activating downstream signaling leading to IRF3, NF- $\kappa$ B and MAP kinases (Figure 4). Overexpression of RIG-I confers antiviral responses, and conventional DCs and fibroblasts derived from RIG-I-deficient mice are unable to produce type I IFN and inflammatory cytokines after NDV, SeV and VSV infections. ${ }^{79,80}$

Melanoma differentiation-associated gene 5 (Mda5) (also known as Helicard) is structurally similar to RIG-I, which also contains two CARD-like and a single helicase domain, and is suggested to mediate antiviral responses (Figure 4). ${ }^{81-84}$ LGP2 is also related to RIG-I and Mda5, but lacks the CARDlike domains, and is therefore suggested to function as a negative regulator for RIG-I and Mda5 (Figure 4). ${ }^{84}$

\section{RIG-I- and Mda-5-Mediated Signaling}

Induction of IFN $\beta$ after virus infection or intracellular administration of dsRNA is abolished in embryonic fibroblast cells prepared from TBK1 and IKKi doubly deficient mice. ${ }^{60}$ It is therefore possible that RIG-I and Mda5 utilize an adapter molecules containing a similar CARD structure that links these helicases to TBK1 and IKKi. Recently, interferon promoter stimulator-1 (IPS-1) (also known as mitochondrial antiviral signaling protein (MAVS), virus-induced signaling adapter (VISA) or Cardif) has been identified as a potent activator of IFN $\beta$ promoter that contains an $\mathrm{N}$-terminal CARD domain (Figure 4). ${ }^{85-88}$ IPS-1 interacts with RIG-I and Mda5 via the CARD domain. Overexpression of IPS-1 activated IFN $\alpha$ and NF- $\kappa$ B promoters in addition to IFN $\beta$ promoter, and blocked viral replication. ${ }^{85-88}$ Conversely, knockdown of IPS1 by siRNA reduced type I IFN induction in response to viruses and enhanced virus replication. ${ }^{85,86}$ Fas-associated death domain (FADD) and RIP1, which were originally identified to associate with the TNF receptor family of death receptors, are 


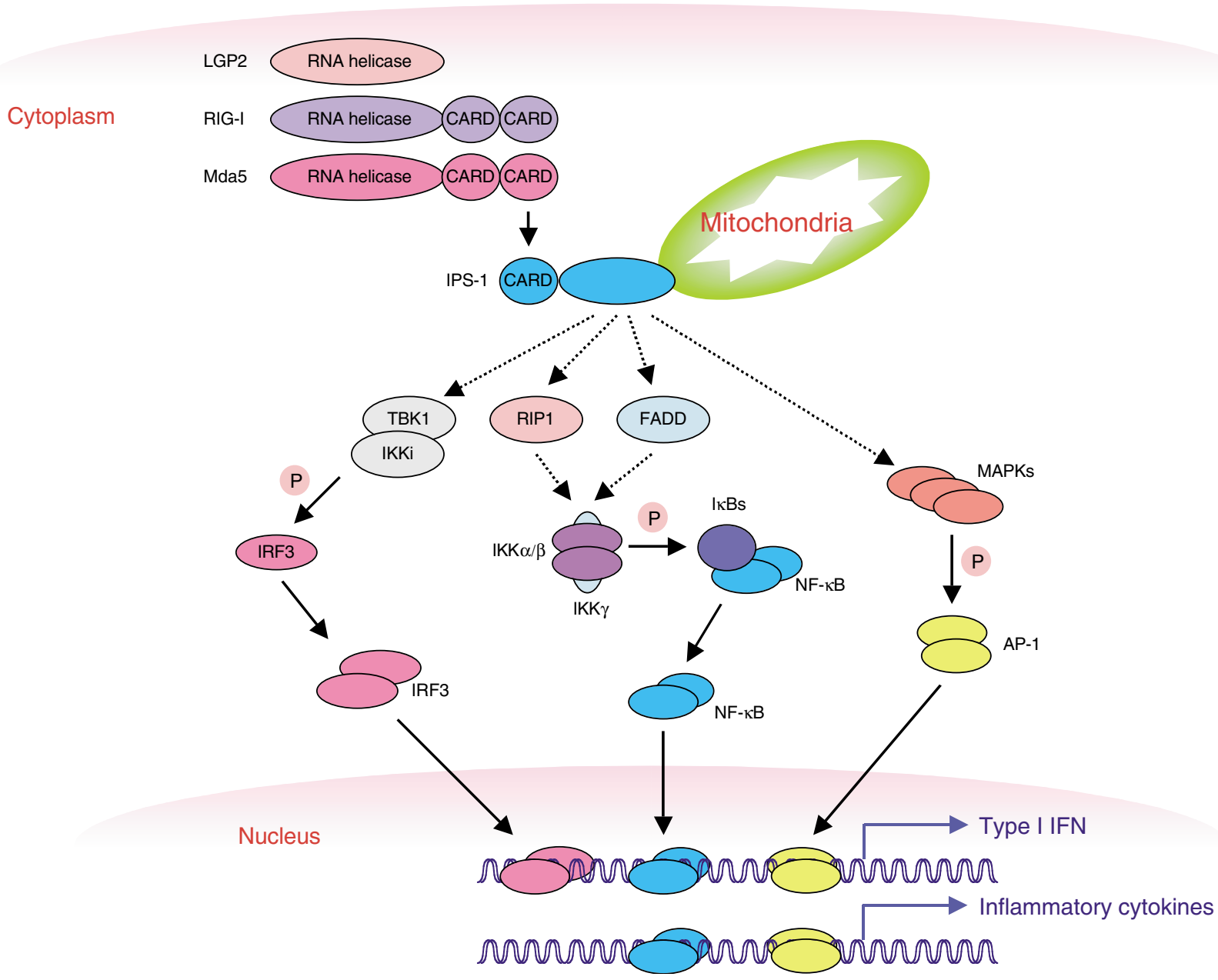

Figure 4 RIG-I- and Mda5-mediated signaling pathway. Cells express cytoplasmic RNA helicases (RIG-I, Mda5 and LGP2) that recognize actively replicating viruses. RIG-I and Mda5 contain CARD-like structures that are required for signaling. The CARDs of these helicases interact with an adapter IPS-1 (also known as MAVS, VISA or Cardif). IPS-1 localizes in mitochondria and initiates intracellular signaling pathways leading to IRF3, NF- $\kappa$ B and AP-1 via TBK1/IKKi, IKK $\alpha / / \mathrm{KK} \beta$ and MAP kinases, respectively. FADD and RIP1 are implicated in RIG-I- and Mda5-dependent pathways. Both FADD and RIP1 activate NF- $\kappa$ B, and IPS-1 facilitates FADD- and RIP-1mediated NF- $\kappa$ B activation. However, the precise mechanisms of how IPS-1 activates IRF3, NF- $\kappa$ B and AP-1 remain unclear

implicated in virus infection-induced type I IFN induction. ${ }^{89}$ IPS-1 interacts with FADD and RIP-1 via non-CARD region to facilitate NF- $\kappa \mathrm{B}$, rather than IRF3 activation (Figure 4). ${ }^{85}$

Seth et al. ${ }^{86}$ demonstrated that MAVS contains a potential transmembrane domain in the C-terminus, which is required for targeting MAVS to the mitochondria (Figure 4). Importantly, they showed that mitochondrial retention of MAVS is essential for IRF3 and NF- $\kappa \mathrm{B}$ activation, suggesting that signaling from mitochondria plays important roles in antiviral responses. Meylan et al. ${ }^{88}$ demonstrated that NS3/4A serine protease in hepatitis $\mathrm{C}$ virus (HCV) targets Cardif for cleavage. A putative cleavage site is located upstream of the transmembrane domain, and they demonstrated that $\mathrm{HCV}$ infection results in cleavage of Cardif by using cell culture infection system. Notably, overexpression of a cleaved form of Cardif that lacks the transmembrane region had no ability to activate IFN $\beta$ and NF- $\kappa$ B. Collectively, NS3/4A is likely to change the cellular localization of Cardif from mitochondria to cytoplasm by cleavage, thereby inhibiting type I IFN and inflammatory responses. Xu et al. ${ }^{87}$ found that VISA contains two TRAF6-binding domains, and interacts with TRAF6 through these domains. They also demonstrated that VISA-TRAF6 interaction is required for NF- $\kappa$ B but not IRF3 activation. However, the requirement for TRAF6 in virus infection-mediated signaling is controversial. ${ }^{85,86}$ Furthermore, Xu et al. provided evidence showing that VISA interacts with Trif, while other groups have demonstrated that VISA is not involved in the Trif-dependent pathway. ${ }^{85-87}$ To clarify these discrepancies, the generation of IPS-1/MAVS/VISA/ Cardif knockout mice will be required.

\section{Conclusion and Future Perspectives}

TLRs play essential roles in innate immune responses by recognizing various pathogen-derived components. TLRs activate the conserved MyD88-dependent pathway leading to $\mathrm{NF}-\kappa \mathrm{B}$ and $\mathrm{AP}-1$, which are responsible for inflammatory 
responses. In addition, TLRs also mediate alternative pathways by utilizing a specific combination of adapter molecules to mount appropriate immune responses. For example, TLR3, TLR4, TLR7/8 and TLR9 induce type I IFN responses. TLR3 and TLR4 induce IFN $\beta$ via a Trif $>$ TBK1/IKKi $>$ IRF3 pathway, while TLR7/8 and TLR9 induce type I IFN by pDCs via a MyD88 > IRAK1 > IRF7 pathway. PDCs express TLR7/8 and TLR9, but not other TLRs. Moreover, IRF7 is constitutively expressed in pDCs, but not in other types of cells, accounting for the mechanisms of pDCs' ability to rapidly produce huge amounts of type I IFN in response to TLR7/8 and TLR9 ligands. It appears that there is a TLR-independent pathway to recognize viral components. In particular, RIG-I and Mda5 serve as cytoplasmic sensors for virus infections that activate antiviral immune responses. IPS-1/MAVS/VISA/Cardif is most likely an adapter interacting with RIG-I and Mda5 that mediates IRF3, IRF7, NF- $\kappa \mathrm{B}$ and AP-1 activations. Collectively, host cells possess multiple defensive mechanisms against viral infection. Further understanding of the molecular pathways of TLRs and RIG-I/Mda5 will lead to novel strategies for controlling infectious diseases.

\section{References}

1. Akira S, Takeda $K$ and Kaisho $T$ (2001) Toll-like receptors: critical proteins linking innate and acquired immunity. Nat. Immunol. 2: 675-680

2. Lemaitre B, Nicolas E, Michaut L, Reichhart JM and Hoffmann JA (1996) The dorsoventral regulatory gene cassette spatzle/Toll/cactus controls the potent antifungal response in Drosophila adults. Cell 86: 973-983

3. Hoffmann JA (2003) The immune response of Drosophila. Nature 426: 33-38

4. Medzhitov R, Preston-Hurlburt P and Janeway CJ (1997) A human homologue of the Drosophila Toll protein signals activation of adaptive immunity. Nature 388: 394-397

5. Poltorak A, He X, Smirnova I, Liu MY, Van Huffel C, Du X, Birdwell D, Alejos E, Silva M, Galanos C, Freudenberg M, Ricciardi-Castagnoli $P$, Layton B and Beutler B (1998) Defective LPS signaling in C3H/HeJ and C57BL/10ScCr mice: mutations in Trr4 gene. Science 282: 2085-2088

6. Hoshino K, Takeuchi O, Kawai T, Sanjo H, Ogawa T, Takeda Y, Takeda K and Akira S (1999) Toll-like receptor 4 (TLR4)-deficient mice are hyporesponsive to lipopolysaccharide: evidence for TLR4 as the Lps gene product. J. Immunol. 162: 3749-3752

7. Takeda $\mathrm{K}$ and Akira S (2005) Toll-like receptors in innate immunity. Int. Immunol. 17: 1-14

8. Takeuchi O, Hoshino K, Kawai T, Sanjo H, Takada H, Ogawa T, Takeda K and Akira S (1999) Differential roles of TLR2 and TLR4 in recognition of gramnegative and gram-positive bacterial cell wall components. Immunity 11: 443-451

9. Takeuchi O, Kaufmann A, Grote K, Kawai T, Hoshino K, Morr M, Muhlradt PF and Akira S (2000) Preferentially the R-stereoisomer of the mycoplasmal lipopeptide macrophage-activating lipopeptide-2 activates immune cells through a toll-like receptor 2- and MyD88-dependent signaling pathway. J. Immunol. 164: 554-557

10. Takeuchi O, Sato S, Horiuchi T, Hoshino K, Takeda K, Dong Z, Modlin RL and Akira S (2002) Role of Toll-like receptor 1 in mediating immune response to microbial lipoproteins. J. Immunol. 169: 10-14

11. Takeuchi O, Kawai T, Muhlradt PF, Morr M, Radolf JD, Zychlinsky A, Takeda K and Akira S (2001) Discrimination of bacterial lipoproteins by Toll-like receptor 6. Int. Immunol. 13: 933-940

12. Ozinsky A, Underhill DM, Fontenot JD, Hajjar AM, Smith KD, Wilson $C B$, Schroeder $L$ and Aderem A (2000) The repertoire for pattern recognition of pathogens by the innate immune system is defined by cooperation between toll-like receptors. Proc. Natl. Acad. Sci. USA 97: 13766-13771
13. Alexopoulou L, Holt AC, Medzhitov R and Flavell RA (2001) Recognition of double-stranded RNA and activation of NF-kappaB by Toll-like receptor 3 . Nature 413: 732-738

14. Hayashi F, Smith KD, Ozinsky A, Hawn TR, Yi EC, Goodlett DR, Eng JK, Akira $S$, Underhill DM and Aderem A (2001) The innate immune response to bacterial flagellin is mediated by Toll-like receptor 5. Nature 410: 1099-1103

15. Zhang D, Zhang G, Hayden MS, Greenblatt MB, Bussey C, Flavell RA and Ghosh S (2004) A toll-like receptor that prevents infection by uropathogenic bacteria. Science 303: 1522-1526

16. Yarovinsky F, Zhang D, Andersen JF, Bannenberg GL, Serhan CN, Hayden MS, Hieny S, Sutterwala FS, Flavell RA, Ghosh S and Sher A (2005) TLR11 activation of dendritic cells by a protozoan profilin-like protein. Science 308 : 1626-1629

17. Hemmi H, Kaisho T, Takeuchi O, Sato S, Sanjo H, Hoshino K, Horiuchi T, Tomizawa H, Takeda K and Akira S (2002) Small anti-viral compounds activate immune cells via the TLR7 MyD88-dependent signaling pathway. Nat. Immunol. 3: 196-200

18. Diebold SS, Kaisho T, Hemmi H, Akira S and Reis e Sousa C (2004) Innate antiviral responses by means of TLR7-mediated recognition of single-stranded RNA. Science 303: 1529-1531

19. Heil F, Hemmi H, Hochrein H, Ampenberger F, Kirschning C, Akira S, Lipford G, Wagner $\mathrm{H}$ and Bauer $\mathrm{S}$ (2004) Species-specific recognition of single-stranded RNA via toll-like receptor 7 and 8. Science 303: 1526-1529

20. Heil F, Ahmad-Nejad P, Hemmi H, Hochrein H, Ampenberger F, Gellert T, Dietrich H, Lipford G, Takeda K, Akira S, Wagner H and Bauer S (2003) The Toll-like receptor 7 (TLR7)-specific stimulus loxoribine uncovers a strong relationship within the TLR7 8 and 9 subfamily. Eur. J. Immunol. 33: 2987-2997

21. Jurk M, Heil F, Vollmer J, Schetter C, Krieg AM, Wagner H, Lipford G and Bauer $S$ (2002) Human TLR7 or TLR8 independently confer responsiveness to the antiviral compound R-848. Nat. Immunol. 3: 499

22. Lund JM, Alexopoulou L, Sato A, Karow M, Adams NC, Gale NW, Iwasaki A and Flavell RA (2004) Recognition of single-stranded RNA viruses by Toll-like receptor 7. Proc. Natl. Acad. Sci. USA 101: 5598-5603

23. Hornung V, Guenthner-Biller M, Bourquin C, Ablasser A, Schlee M, Uematsu S, Noronha A, Manoharan M, Akira S, de Fougerolles A, Endres S and Hartmann $G$ (2005) Sequence-specific potent induction of IFN-alpha by short interfering RNA in plasmacytoid dendritic cells through TLR7. Nat. Med. 11: 263-270

24. Hemmi H, Takeuchi O, Kawai T, Kaisho T, Sato S, Sanjo H, Matsumoto M, Hoshino K, Wagner H, Takeda K and Akira S (2000) A Toll-like receptor recognizes bacterial DNA. Nature 408: 740-745

25. Krug A, French AR, Barchet W, Fischer JA, Dzionek A, Pingel JT, Orihuela MM, Akira S, Yokoyama WM and Colonna M (2004) TLR9-dependent recognition of MCMV by IPC and DC generates coordinated cytokine responses that activate antiviral NK cell function. Immunity 21: 107-119

26. Lund J, Sato A, Akira S, Medzhitov R and Iwasaki A (2003) Toll-like receptor 9mediated recognition of Herpes simplex virus-2 by plasmacytoid dendritic cells. J. Exp. Med. 198: 513-520

27. Coban C, Ishii KJ, Kawai T, Hemmi H, Sato S, Uematsu S, Yamamoto M, Takeuchi O, Itagaki S, Kumar N, Horii T and Akira S (2005) Toll-like receptor 9 mediates innate immune activation by the malaria pigment hemozoin. J. Exp. Med. 201: 19-25

28. Iwasaki A and Medzhitov R (2004) Toll-like receptor control of the adaptive immune responses. Nat. Immunol. 5: 987-995

29. Akira S and Takeda K (2004) Toll-like receptor signalling. Nat. Rev. Immunol. 4: $499-511$

30. Karin M and Greten FR (2005) NF-kappaB: linking inflammation and immunity to cancer development and progression. Nat. Rev. Immunol. 5: 749-759

31. Shaulian E and Karin M (2002) AP-1 as a regulator of cell life and death. Nat. Cell. Biol. 4: 131-136

32. Kobayashi K, Hernandez LD, Galan JE, Janeway Jr. CA, Medzhitov R and Flavell RA (2002) IRAK-M is a negative regulator of Toll-like receptor signaling. Cell 110: 191-202

33. Suzuki N, Suzuki S, Duncan GS, Millar DG, Wada T, Mirtsos C, Takada H, Wakeham A, Itie A, Li S, Penninger JM, Wesche H, Ohashi PS, Mak TW and Yeh WC (2002) Severe impairment of interleukin-1 and Toll-like receptor signalling in mice lacking IRAK-4. Nature 416: 750-756

34. Picard C, Puel A, Bonnet M, Ku CL, Bustamante J, Yang K, Soudais C, Dupuis S, Feinberg J, Fieschi C, Elbim C, Hitchcock R, Lammas D, Davies G, Al-Ghonaium A, Al-Rayes H, Al-Jumaah S, Al-Hajjar S, Al-Mohsen IZ, Frayha 
HH, Rucker R, Hawn TR, Aderem A, Tufenkeji H, Haraguchi S, Day NK, Good RA, Gougerot-Pocidalo MA, Ozinsky A and Casanova JL (2003) Pyogenic bacterial infections in humans with IRAK-4 deficiency. Science 299: 2076-2079

35. Chen ZJ (2005) Ubiquitin signalling in the NF-kappaB pathway. Nat. Cell Biol. 7: 758-765

36. Sun $L$ and Chen ZJ (2004) The novel functions of ubiquitination in signaling. Curr. Opin. Cell Biol. 16: 119-126

37. Sato S, Sanjo H, Takeda K, Ninomiya-Tsuji J, Yamamoto M, Kawai T, Matsumoto K, Takeuchi O and Akira S (2005) Essential function for the kinase TAK1 in innate and adaptive immune responses. Nat. Immunol. 6: 1087-1095

38. Huang Q, Yang J, Lin Y, Walker C, Cheng J, Liu ZG and Su B (2004) Differential regulation of interleukin 1 receptor and Toll-like receptor signaling by MEKK3. Nat. Immunol. 5: 98-103

39. Dumitru CD, Ceci JD, Tsatsanis C, Kontoyiannis D, Stamatakis K, Lin JH, Patriotis C, Jenkins NA, Copeland NG, Kollias G and Tsichlis PN (2000) TNFalpha induction by LPS is regulated posttranscriptionally via a TpI2/ERKdependent pathway. Cell 103: 1071-1083

40. Sugimoto K, Ohata M, Miyoshi J, Ishizaki H, Tsuboi N, Masuda A, Yoshikai Y, Takamoto M, Sugane K, Matsuo S, Shimada Y and Matsuguchi T (2004) A serine/threonine kinase Cot/Tpl2 modulates bacterial DNA-induced IL-12 production and Th cell differentiation. J. Clin. Invest. 114: 857-866

41. Yamamoto M, Sato S, Hemmi H, Sanjo H, Uematsu S, Kaisho T, Hoshino K, Takeuchi O, Kobayashi M, Fujita T, Takeda K and Akira S (2002) Essential role for TIRAP in activation of the signalling cascade shared by TLR2 and TLR4. Nature 420: 324-329

42. Horng T, Barton GM, Flavell RA and Medzhitov R (2002) The adaptor molecule TIRAP provides signalling specificity for Toll-like receptors. Nature 420: 329-333

43. Kawai T, Takeuchi O, Fujita T, Inoue J, Muhlradt PF, Sato S, Hoshino K and Akira S (2001) Lipopolysaccharide stimulates the MyD88-independent pathway and results in activation of IFN-regulatory factor 3 and the expression of a subset of lipopolysaccharide-inducible genes. J. Immunol. 167: 5887-5894

44. Hacker H, Vabulas R.M, Takeuchi O, Hoshino K, Akira S and Wagner H (2000) Immune cell activation by bacterial CpG-DNA through myeloid differentiation marker 88 and tumor necrosis factor receptor-associated factor (TRAF)6. J. Exp. Med. 192: 595-600

45. Schnare M, Holt A.C, Takeda K, Akira S and Medzhitov R (2000) Recognition of CpG DNA is mediated by signaling pathways dependent on the adaptor protein MyD88. Curr. Biol. 10: 1139-1142

46. Kawai T, Adachi O, Ogawa T, Takeda K and Akira S (1999) Unresponsiveness of MyD88-deficient mice to endotoxin. Immunity 11: 115-122

47. Theofilopoulos AN, Baccala R, Beutler B and Kono DH (2005) Type I interferons (alpha/beta) in immunity and autoimmunity. Annu. Rev. Immunol. 23: $307-336$

48. Yamamoto M, Sato S, Mori K, Hoshino K, Takeuchi O, Takeda K and Akira S (2002) A novel Toll//L-1 receptor domain-containing adapter that preferentially activates the IFN-beta promoter in the Toll-like receptor signaling. J. Immunol. 169: $6668-6672$

49. Oshiumi H, Matsumoto M, Funami K, Akazawa T and Seya T (2003) TICAM-1 an adaptor molecule that participates in Toll-like receptor 3-mediated interferon-beta induction. Nat. Immunol. 4: 161-167

50. Yamamoto M, Sato S, Hemmi H, Hoshino K, Kaisho T, Sanjo H, Takeuchi O, Sugiyama M, Okabe M, Takeda K and Akira S (2003) Role of adaptor TRIF in the MyD88-independent toll-like receptor signaling pathway. Science 301 : 640-643

51. Hoebe K, Du X, Georgel P, Janssen E, Tabeta K, Kim SO, Goode J, Lin P, Mann N, Mudd S, Crozat K, Sovath S, Han J and Beutler B (2003) Identification of Lps2 as a key transducer of MyD88-independent TIR signalling. Nature 424: 743-748

52. Yamamoto M, Sato S, Hemmi H, Uematsu S, Hoshino K, Kaisho T, Takeuchi $\mathrm{O}$, Takeda $\mathrm{K}$ and Akira S (2003) TRAM is specifically involved in the Toll-like receptor 4-mediated MyD88-independent signaling pathway. Nat. Immunol. 4: $1144-1150$

53. Meylan E, Burns K, Hofmann K, Blancheteau V, Martinon F, Kelliher M and Tschopp J (2004) RIP1 is an essential mediator of Toll-like receptor 3-induced NF-kappaB activation. Nat. Immunol. 5: 503-507

54. Cusson-Hermance N, Lee TH, Fitzgerald KA and Kelliher MA (2005) Rip1 mediates the Trif-dependent toll-like receptor 3 and 4-induced NF-kappa B activation but does not contribute to IRF-3 activation. J. Biol. Chem. 280: 36560-36566

55. Sato S, Sugiyama M, Yamamoto M, Watanabe Y, Kawai T, Takeda K and Akira S (2003) Toll/L-1 receptor domain-containing adaptor inducing IFN-beta (TRIF) associates with TNF receptor-associated factor 6 and TANK-binding kinase 1 and activates two distinct transcription factors NF-kappa B and IFN-regulatory factor-3 in the Toll-like receptor signaling. J. Immunol. 171: 4304-4310

56. Gohda J, Matsumura T and Inoue J (2004) TNFR-associated factor (TRAF) 6 is essential for MyD88-dependent pathway but not toll/L-1 receptor domaincontaining adaptor-inducing IFN-beta (TRIF)-dependent pathway in TLR signaling. J. Immunol. 173: 2913-2917

57. Sharma S, tenOever BR, Grandvaux N, Zhou GP, Lin R and Hiscott J (2003) Triggering the interferon antiviral response through an IKK-related pathway. Science 300: 1148-1151

58. Fitzgerald KA, McWhirter SM, Faia KL, Rowe DC, Latz E, Golenbock DT, Coyle AJ, Liao SM and Maniatis T (2003) IKKepsilon and TBK1 are essential components of the IRF3 signaling pathway. Nat. Immunol. 4: 491-496

59. McWhirter SM, Fitzgerald KA, Rosains J, Rowe DC, Golenbock DT and Maniatis T (2004) IFN-regulatory factor 3-dependent gene expression is defective in Tbk1-deficient mouse embryonic fibroblasts. Proc. Natl. Acad. Sci. USA 101: 233-238

60. Hemmi H, Takeuchi O, Sato S, Yamamoto M, Kaisho T, Sanjo H, Kawai T, Hoshino K, Takeda K and Akira S (2004) The roles of two IkappaB kinaserelated kinases in lipopolysaccharide and double stranded RNA signaling and viral infection. J. Exp. Med. 199: 1641-1650

61. Perry AK, Chow EK, Goodnough JB, Yeh WC and Cheng G (2004) Differential requirement for TANK-binding kinase-1 in type I interferon responses to Tolllike receptor activation and viral infection. J. Exp. Med. 199: 1651-1658

62. Colonna M, Trinchieri G and Liu YJ (2004) Plasmacytoid dendritic cells in immunity. Nat. Immunol. 5: 1219-1226

63. Liu YJ (2005) IPC: professional type 1 interferon-producing cells and plasmacytoid dendritic cell precursors. Annu. Rev. Immunol. 23: 275-306

64. Honda K, Yanai H, Negishi H, Asagiri M, Sato M, Mizutani T, Shimada N, Ohba Y, Takaoka A, Yoshida N and Taniguchi T (2005) IRF-7 is the master regulator of type-I interferon-dependent immune responses. Nature 434: 772-777

65. Kawai T, Sato S, Ishii K.J, Coban C, Hemmi H, Yamamoto M, Terai K, Matsuda M, Inoue J, Uematsu S, Takeuchi O and Akira S (2004) Interferon-alpha induction through Toll-like receptors involves a direct interaction of IRF7 with MyD88 and TRAF6. Nat. Immunol. 5: 1061-1068

66. Honda K, Yanai H, Mizutani T, Negishi H, Shimada N, Suzuki N, Ohba Y, Takaoka A, Yeh WC and Taniguchi T (2004) Role of a transductionaltranscriptional processor complex involving MyD88 and IRF-7 in Toll-like receptor signaling. Proc. Natl. Acad. Sci. USA 101: 15416-15421

67. Hemmi H, Kaisho T, Takeda K and Akira S (2003) The roles of Toll-like receptor 9 MyD88 and DNA-dependent protein kinase catalytic subunit in the effects of two distinct CpG DNAs on dendritic cell subsets. J. Immunol. 170: 3059-3064

68. Coccia EM, Severa M, Giacomini E, Monneron D, Remoli ME, Julkunen I, Cella M, Lande R and Uze G (2004) Viral infection and Toll-like receptor agonists induce a differential expression of type I and lambda interferons in human plasmacytoid and monocyte-derived dendritic cells. Eur. J. Immunol. 34: 796-805

69. Dai J, Megjugorac NJ, Amrute SB and Fitzgerald-Bocarsly P (2004) Regulation of IFN regulatory factor-7 and IFN-alpha production by enveloped virus and lipopolysaccharide in human plasmacytoid dendritic cells. J. Immunol. 173: 1535-1548

70. Uematsu S, Sato S, Yamamoto M, Hirotani T, Kato H, Takeshita F, Matsuda M, Coban C, Ishii KJ, Kawai T, Takeuchi O and Akira S (2005) Interleukin-1 receptor-associated kinase-1 (IRAK-1) plays an essential role for TLR7- and TLR9-mediated interferon- $\alpha$ induction. J. Exp. Med. 201: 915-923

71. Takaoka A, Yanai H, Kondo S, Duncan G, Negishi H, Mizutani T, Kano SI, Honda K, Ohba Y, Mak TW and Taniguchi T (2005) Integral role of IRF-5 in the gene induction programme activated by Toll-like receptors. Nature 434: 243-249

72. Lin R, Yang L, Arguello M, Penafuerte C and Hiscott J (2005) A CRM1dependent nuclear export pathway is involved in the regulation of IRF-5 subcellular localization. J. Biol. Chem. 280: 3088-3095 
73. Schoenemeyer A, Barnes BJ, Mancl ME, Latz E, Goutagny N, Pitha PM, Fitzgerald KA and Golenbock DT (2005) The interferon regulatory factor IRF5 is a central mediator of TLR7 signaling. J. Biol. Chem. 280: $17005-17012$

74. Tsujimura H, Tamura T, Kong HJ, Nishiyama A, Ishii KJ, Klinman DM and Ozato K (2004) Toll-like receptor 9 signaling activates NF-kappaB through IFN regulatory factor-8/IFN consensus sequence binding protein in dendritic cells. J. Immunol. 172: 6820-6827

75. Hornung V, Schlender J, Guenthner-Biller M, Rothenfusser S, Endres S, Conzelmann KK and Hartmann G (2004) Replication-dependent potent IFNalpha induction in human plasmacytoid dendritic cells by a single-stranded RNA virus. J. Immunol. 173: 5935-5943

76. Krug A, Luker GD, Barchet W, Leib DA, Akira S and Colonna M (2004) Herpes simplex virus type 1 activates murine natural interferon-producing cells through toll-like receptor 9. Blood 103: 1433-1437

77. Edelmann KH, Richardson-Burns S, Alexopoulou L, Tyler KL, Flavell RA and Oldstone MB (2004) Does Toll-like receptor 3 play a biological role in virus infections? Virology 322: 231-238

78. Lopez CB, Moltedo B, Alexopoulou L, Bonifaz L, Flavell RA and Moran TM (2004) TLR-independent induction of dendritic cell maturation and adaptive immunity by negative-strand RNA viruses. J. Immunol. 173: 6882-6889

79. Yoneyama M, Kikuchi M, Natsukawa T, Shinobu N, Imaizumi T, Miyagishi M, Taira K, Akira S and Fujita T (2004) The RNA helicase RIG-I has an essential function in double-stranded RNA-induced innate antiviral responses. Nat. Immunol. 5: 730-737

80. Kato H, Sato S, Yoneyama M, Yamamoto M, Uematsu S, Matsui K, Tsujimura T, Takeda K, Fujita T, Takeuchi O and Akira S (2005) Cell type specific involvement of RIG-I in antiviral response. Immunity 23: 19-28
81. Kang DC, Gopalkrishnan RV, Wu Q, Jankowsky E, Pyle AM and Fisher PB (2002) mda-5: An interferon-inducible putative RNA helicase with doublestranded RNA-dependent ATPase activity and melanoma growth-suppressive properties. Proc. Natl. Acad. Sci. USA 99: 637-642

82. Kovacsovics M, Martinon F, Micheau O, Bodmer JL, Hofmann K and Tschopp J (2002) Overexpression of Helicard a CARD-containing helicase cleaved during apoptosis accelerates DNA degradation. Curr. Biol. 12: 838-843

83. Andrejeva J, Childs KS, Young DF, Carlos TS, Stock N, Goodbourn S and Randall RE (2004) The V proteins of paramyxoviruses bind the IFN-inducible RNA helicase mda-5 and inhibit its activation of the IFN-beta promoter. Proc. Natl. Acad. Sci. USA 101: 17264-17269

84. Yoneyama M, Kikuchi M, Matsumoto K, Imaizumi T, Miyagishi M, Taira K, Foy E, Loo YM, Gale MJ, Akira S, Yonehara S, Kato A and Fujita T (2005) Shared and unique functions of the DExD/H-Box helicases RIG-I MDA5 and LGP2 in antiviral innate immunity. J. Immunol. 175: 2851-2858

85. Kawai T, Takahashi K, Sato S, Coban C, Kumar H, Kato H, Ishii KJ, Takeuchi O and Akira S (2005) IPS-1; an adaptor triggering RIG-I- and Mda5-mediated type I interferon induction. Nat. Immunol. 6: 981-988

86. Seth RB, Sun L, Ea CK and Chen ZJ (2005) Identification and characterization of MAVS a mitochondrial antiviral signaling protein that activates NF-kappaB and IRF3. Cell 122: 669-682

87. Xu LG, Wang YY, Han KJ, Li LY, Zhai Z and Shu HB (2005) VISA Is an adapter protein required for virus-triggered IFN-beta signaling. Mol. Cell 19: 727-740

88. Meylan E, Curran J, Hofmann K, Moradpour D, Binder M, Bartenschlager R and Tschopp J (2005) Cardif is an adaptor protein in the RIG-I antiviral pathway and is targeted by hepatitis $C$ virus. Nature 437: 1167-1172

89. Balachandran S, Thomas E and Barber GN (2004) A FADD-dependent innate immune mechanism in mammalian cells. Nature 432: 401-405 